\title{
The effect of exercise therapy combined with psychological therapy on physical activity and quality of life in patients with painful diabetic neuropathy
}

Citation for published version (APA):

van Laake-Geelen, C. C. M., Smeets, R. J. E. M., Quadflieg, S. P. A. B., Kleijnen, J., \& Verbunt, J. A. (2019). The effect of exercise therapy combined with psychological therapy on physical activity and quality of life in patients with painful diabetic neuropathy: a systematic review. Scandinavian Journal of Pain, 19(3), 433-439. https://doi.org/10.1515/sjpain-2019-0001

Document status and date:

Published: 01/07/2019

DOI:

10.1515/sjpain-2019-0001

Document Version:

Publisher's PDF, also known as Version of record

Document license:

Taverne

Please check the document version of this publication:

- A submitted manuscript is the version of the article upon submission and before peer-review. There can be important differences between the submitted version and the official published version of record.

People interested in the research are advised to contact the author for the final version of the publication, or visit the DOI to the publisher's website.

- The final author version and the galley proof are versions of the publication after peer review.

- The final published version features the final layout of the paper including the volume, issue and page numbers.

Link to publication

\footnotetext{
General rights rights.

- You may freely distribute the URL identifying the publication in the public portal. please follow below link for the End User Agreement:

www.umlib.nl/taverne-license

Take down policy

If you believe that this document breaches copyright please contact us at:

repository@maastrichtuniversity.nl

providing details and we will investigate your claim.
}

Copyright and moral rights for the publications made accessible in the public portal are retained by the authors and/or other copyright owners and it is a condition of accessing publications that users recognise and abide by the legal requirements associated with these

- Users may download and print one copy of any publication from the public portal for the purpose of private study or research.

- You may not further distribute the material or use it for any profit-making activity or commercial gain

If the publication is distributed under the terms of Article $25 \mathrm{fa}$ of the Dutch Copyright Act, indicated by the "Taverne" license above, 


\section{Systematic review}

Charlotte C.M. van Laake-Geelen*, Rob J.E.M. Smeets, Suzan P.A.B. Quadflieg, Jos Kleijnen and Jeanine $A$. Verbunt

\section{The effect of exercise therapy combined with psychological therapy on physical activity and quality of life in patients with painful diabetic neuropathy: a systematic review}

https://doi.org/10.1515/sjpain-2019-0001

Received January 3, 2019; revised April 10, 2019; accepted April 15, 2019

\section{Abstract}

Background and aims: Approximately 25\% of patients with diabetes mellitus type 2 (DMII) develop painful diabetic neuropathy (PDN). PDN is known to affect both mental and physical wellbeing, resulting in anxiety, depression, low quality of life and physical disability. Pharmacological treatment of PDN aims at pain relief and is often ineffective and/or has many side effects. Rehabilitation treatment modalities that are designed to help the patient deal with PDN related complaints, are mostly focussed on either physical (e.g. exercise therapy) or psychological aspects (e.g. cognitive behavioural therapy, CBT). There is emerging evidence that PDN can be approached from a biopsychosocial perspective, in which physical and psychosocial aspects are integrated. From this biopsychosocial approach it is plausible that integrated treatment modalities such as acceptance commitment therapy (ACT) or exposure in vivo (EXP) could

\footnotetext{
*Corresponding author: Charlotte C.M. van Laake-Geelen, MD, Department of Rehabilitation Medicine, Research School CAPHRI, Maastricht University, Maastricht, The Netherlands; and Adelante Centre of Expertise in Rehabilitation and Audiology, P.0. Box 88, 6430 AB Hoensbroek, The Netherlands, Phone: + 31455282828 , E-mail: c.laake@adelante-zorggroep.nl

Rob J.E.M. Smeets: Department of Rehabilitation Medicine, Research School CAPHRI, Maastricht University, Maastricht, The Netherlands; and CIR Revalidatie, Eindhoven, The Netherlands Suzan P.A.B. Quadflieg: Department of Rehabilitation Medicine, Research School CAPHRI, Maastricht University, Maastricht, The Netherlands

Jos Kleijnen: Department of Family Medicine, Research School CAPHRI, Maastricht University, Maastricht, The Netherlands Jeanine A. Verbunt: Department of Rehabilitation Medicine, Research School CAPHRI, Maastricht University, Maastricht, The Netherlands; and Adelante Centre of Expertise in Rehabilitation and Audiology, Hoensbroek, The Netherlands
}

be effective in patients with PDN. The objective of this review was to provide an overview of the current evidence on the effects of rehabilitation treatments that combine exercise therapies with psychological therapies in order to improve physical activity (PA) and quality of life (QoL) in patients with PDN.

Methods: Systematic review of the current literature. EMBASE, MEDLINE, Medline In-Process citations and e-Pubs ahead-of-print, Pedro, Web of Science, PsycINFO, CENTRAL, PubMed and Google Scholar were searched. All studies on interventions combining exercise therapy with psychological interventions in patients with PDN, aged $>18$ years, were included. Outcome measures were PA, QoL. Results: The search resulted in 1603 records after removing duplicates. After screening on titles and abstracts, 100 records remained. From these, not one study reported on interventions that combined exercise therapy with psychological interventions. Through a secondary hand search, a total of three reviews were identified that described a total of five studies regarding either physical or psychological interventions in patients with PDN. These studies reported moderate effects of (1) mindfulness meditation on QoL, (2) CBT on pain severity, (3) mindfulness-based stress reduction intervention on function, health-related QoL, pain catastrophizing and depression, (4) aerobic exercise on QoL and (5) Tai Chi on glucose control, balance, neuropathic symptoms, and some dimensions of QoL in patients with PDN. All studies were of a moderate quality, and results should be interpreted with caution.

Conclusions: Based on increasing knowledge in the domain of chronic pain, it could be assumed that integrated rehabilitation treatments for patients with PDN are beneficial. There is no literature to support this and more research should be done on integrated biopsychosocial interventions in patients with PDN.

Implications: This empty review highlights the importance that more research should be done on integrated biopsychosocial interventions in patients with PDN. Currently, our research group is performing a study on the effects of EXP treatment in patients with PDN. 
Keywords: painful diabetic neuropathy; review; rehabilitation intervention; exercise; psychological coping; quality of life.

\section{Introduction}

Approximately $25 \%$ of patients with diabetes mellitus type 2 (DMII) develop painful diabetic neuropathy (PDN) [1], characterised by pain, paraesthesia and sensory loss [2-4]. Currently, the treatment of PDN is mainly pharmacological [5]. Side effects occur and/or the effects are often limited [6].

PDN can have far-reaching consequences in daily life $[7,8]$. It can lead to sensory loss, the development of pressure ulcers (PU's), balance impairments, an altered gait with potentially an increased risk of falling $[9,10]$. This leads to a more sedentary lifestyle [7] with impaired levels of physical activity [11-13], less engagement in social activities, dependency on others, social isolation, depression and as a result decreased quality of life [14-17]. Depression in turn, can amplify diabetic complications related to suboptimal glycaemic control [18]. Furthermore, patients with PDN can suffer from anxiety and fears, such as fear of pain, fear of falling, fear of disturbed glucose regulation, leading to persistence of the consequences of PDN [12, 19-21]. It seems likely that the overall QoL of patients with PDN can be improved when comorbid anxiety and negative emotions are adequately screened, diagnosed and treated [12, 19, 20, 22].

Increasing physical activity in patients with $\mathrm{DM}$ is known to have favourable effects on diabetes-related outcomes [23, 24], such as improved blood sugar control, decreased body fat, and an improved body reaction to insulin therapy $[25,26]$. Aerobic exercise has shown to improve the QoL in patients with PDN [27]. Unfortunately, dropout rates in physical exercise programmes are high (up to 45\%), due to the occurrence of PU's, overuse injuries and lack of motivation [28, 29]. Therefore, an interdisciplinary therapeutic approach that targets physical and emotional factors has been recommended [16, 17, 19, 30, 31].

Since patients with PDN frequently share the comorbidities of depression and fear (and as a consequence disability) with other chronic pain populations [12, 22], it seems apparent to integrate the knowledge obtained in the treatment populations with other pain syndromes into the field of PDN. Within the fear-avoidance-model (FAM) [32], chronic pain is approached from a biopsychosocial perspective. The model states that negative exaggerated or irrational thoughts (catastrophizing) and fears can give rise to avoidance behaviour, which can lead to significant health consequences such as disuse, disability and depression, further fuelling the vicious cycle of chronic disabling pain $[33,34]$. In line with the FAM model, one could hypothesise that a physical intervention or psychological treatment alone will not suffice to restore QoL and participation in daily life, as these treatment address only one ("bio" or "psycho") component of the model. Research has shown that multidisciplinary rehabilitation interventions that target factors from all biopsychosocial domains, administered by healthcare professionals from different backgrounds, are more effective than physical or psychological interventions alone [35].

The aim of this study was to provide an up-to-date overview of the current evidence on the effects of rehabilitation interventions that combine exercise therapies with psychological therapies in order to improve physical activity (PA) and quality of life (QoL) in patients with PDN.

\section{Methods}

The review protocol was registered with PROSPERO (CRD42018081664).

\subsection{Eligibility criteria}

Studies on interventions combining exercise therapies with psychological therapies in patients with a clear diagnosis of PDN (DM I and II), aged $>18$ years were included in this systematic review. Primary outcome measures were physical activity and QoL.

\subsection{Search}

Ovid's EMBASE, MEDLINE, Medline In-Process citations and e-Pubs ahead-of-print and PsycINFO and in Pedro, Web of Science, CENTRAL in Wiley and PubMed (for the newest publications), were searched. Google Scholar was searched for on-going research. A full overview of search terms in Embase is provided in Supplementary data 1. Subject headings and truncations were modified per database.

\subsection{Selection of studies}

Primarily, randomised controlled trials (RCT's) were included. In case no RCT's were available other study types were included, in order of preference: cohort studies, case 
control, cross over studies, observational studies, single case studies, cross-sectional study and experimental studies. Study selection was performed by two reviewers (CvL and SQ). First, both reviewers selected articles for relevance based on title and abstract. Of all articles that appeared to be relevant, the full text articles were retrieved. Of all duplicates, just one was included. The reference lists of all retrieved articles were hand searched for additional references. Consensus meetings were held to resolve disagreements. If disagreement persisted a third reviewer could be consulted (RS).

\subsection{Quality assessment}

The Cochrane Risk of Bias tool for randomised controlled trials and ROBINS-I for non-randomised studies and interventions was used [36]. The individual results were compared by two reviewers (CvL and $\mathrm{SQ}$ ) and disagreements were resolved through discussion when needed. A third reviewer (RS) was available if consensus could not be reached.

\subsection{Data extraction and reporting of data}

DATA extraction was performed by two reviewers ( $\mathrm{CvL}$ and $\mathrm{SQ}$ ) independently. Due to the expected heterogeneity of the concepts of PA and QoL, a narrative summary of all included studies was given. Information on study characteristics (number of participants, gender, age, type of DM, duration of PDN), descriptions of the intervention and control arm, duration of follow up and the data on the outcome measures PA and QoL was extracted from the selected articles.

\section{Results}

The search resulted in 1603 records after having removed 23 duplicates. After screening on title and abstract, 100 records remained for full text reading and 1503 articles were excluded. The reasons for exclusion were related to: wrong diagnosis $(n=1029$, e.g. chemotherapy induced peripheral neuropathy, non-specific chronic pain, diabetic neuropathy without pain), study design $(n=224$, e.g. descriptive reviews), type of intervention ( $n=180$, e.g. pharmacological), different outcome measures ( $n=47$, e.g. improvement of balance disorders and uncertain gait). From the 100 remaining potentially relevant studies, 96 full texts could be retrieved. After full text reading, additional articles were excluded because of not fulfilling the criteria as set on diagnosis $(n=44)$, study design $(n=28)$, type of intervention $(n=24)$. By contacting the authors of the non-retrievable studies, we obtained 1 additional study, which was excluded since this article did not fulfil the criteria set for intervention. At the end of our study selection, not one study that answered our research question could be included. Therefore, no quality assessment was performed. Figure 1 illustrates the study selection.

Through hand search of the 100 selected articles, we identified a total of eight articles that reported on the

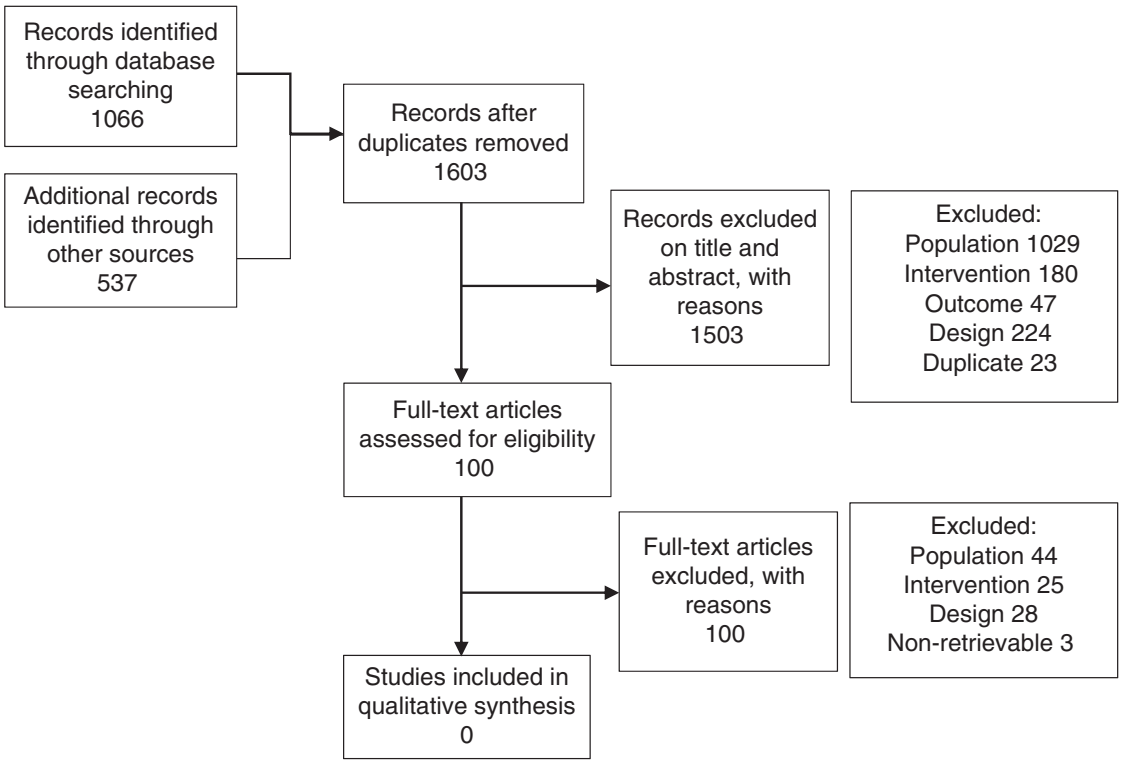

Fig. 1: Flowchart of study selection. 
effectiveness of either a physical or a psychological intervention in patients with PDN (5 RCT's, three reviews). The full overview of these articles with its study characteristics and outcomes is presented in Supplementary data 2.

In short, we identified two studies that investigated exercise based treatments for patients with PDN. A RCT by Dixit et al. [37] showed the positive effects of aerobic exercise compared to usual care, with statistically significant improvement on the following domains of the quality of life in neurological disorders (NeuroQoL) scale: QoL total score, pain subscale, reduced feeling/sensation, sensory motor symptoms and restrictions in daily life activities subscales [37, 38]. A pretest-posttest quasi-experimental design by Ahn and Song [39], reported the positive effect of Tai Chi on glucose control, balance, neuropathic symptoms, and the following dimensions of QoL [Short Form 36 Health Survey (SF36)]: bodily pain subscale, physical functioning, role physical, role emotional, social function in diabetic patients with neuropathy compared to no intervention [39]. We identified 3 RCT's that focused on psychologically based treatments. Teixeira investigated the effect of mindfulness meditation on QoL in patients with PDN compared to care as usual and found no effects symptom related quality of life, measured with NeuroQol and Neuropathic pain scale (NPS) [40]. Otis et al. reported that pain severity and pain interference, measured with the West Haven Yale Multidimensional Pain Inventory (WHYMPI) decreased in the CBT group compared to treatment as usual [41]. Nathan et al. showed that a mindfulness-based stress reduction resulted in significant improvement in function, better health-related quality of life, and reduced pain catastrophizing, and depression compared to those receiving usual care [42]. Results of all studies should be interpreted with caution, as they were of moderate quality.

In 2015, a review was published by Davies et al. [43], which described the studies by Ahn and Song [39], Teixeira [40], Otis et al. [41] and Dixit et al. [37]. Reviews by Rosenberg and Watson [5] and Castelnuovo et al. [44], discussed the work of Otis et al. [41].

\section{Discussion}

The aim of this systematic review was to provide an overview of the current literature regarding the effectiveness of treatments that combine exercise therapy with psychological therapy for the improvement of physical activity and QoL of patients with PDN. Although studies in the domain of chronic pain suggest that a multidisciplinary therapeutic approach based on the biopsychosocial model could be effective in improving physical activity and QoL in patients with PDN, this systematic review of the literature revealed no studies that described or tested treatments that combine exercise therapy with psychological treatment modalities. This so called empty review shows that the biopsychosocial approach in the treatment low levels of physical activity and QoL in patients with PDN is a rather unexplored topic and that studies on the effectiveness of multidisciplinary treatments are needed.

Consequences of PDN can be physical (sensory loss, weakness, pain, physical restrictions), psychological (feelings of loss, feelings of depression, anger, sadness), and social (social withdrawal, isolation, work limitations, lower career opportunities) [13]. PDN has shown to be associated with catastrophic thinking, increased disability, diminished quality of life, depression and anxiety [12, $22,45,46]$. A recent study by our group identified specific fears related to diabetes and pain that showed to be important predictors of physical and social activities; e.g. fear of hypoglycaemia, fear of (increased) pain, fear of total exhaustion, fear of physical injury, fear of falling, fear of loss of identity and fear of negative evaluation [12]. Negative feelings can enhance pain experience and amplify the risk for diabetic complications, again leading to less physical activity and diminished health related quality of life (QoL), creating a vicious cycle [12, 17, 18, 47]. Research has shown that multidisciplinary rehabilitation interventions that target all factors from the different biopsychosocial domains, administered by healthcare professionals from different backgrounds, are more effective than physical or psychological interventions alone [35].

In this review, we identified five studies that reported on the effectiveness of treatments for PDN that are either psychological treatments or exercise interventions alone [37, 39-42]. The results regarding the effectiveness of psychological treatments are not conclusive. A positive, however not statistically significant effect of mindfulness meditation on QoL was found in patients with PDN compared to care as usual [40]. CBT seems to have positive effects on pain severity [41]. A mindfulness-based stress reduction intervention showed improvement in function, better health-related QoL, and reduced pain catastrophizing and depression [42]. We also found limited evidence for exercise-based treatments. Aerobic exercise showed to have positive effects on peripheral neuropathy symptoms [37]. Beneficial effects of Tai Chi on glucose control, balance, neuropathic symptoms, and some dimensions of QoL were found [39]. However, none of these studies supports or rejects a multidisciplinary and/or biopsychosocial approach for PDN. 
A combined physical and cognitive behavioural treatment modality with a potential positive effect is exposure in vivo (EXP) [48-51]. EXP aims to decrease pain-related disability by specifically targeting irrational thoughts and fears about pain and its consequences [32, 52, 53]. EXP treatments have shown to be effective in reducing pain-related fear and the perceived harmfulness of physical activity in various chronic pain conditions, such as chronic low back pain $[51,54,55]$ and complex regional pain syndrome type I (CRPS-I) [50, 54]. Another combined physical and cognitive behavioural treatment modality is acceptance and commitment therapy (ACT) [56]. ACT includes a combination of acceptance and mindfulness methods along with activation and behaviour change methods. Multidisciplinary ACT has shown to be effective in reducing the burden of chronic pain in various pain conditions $[56,57]$. In this review, we have found no articles that discussed EXP or ACT. Currently, our group is conducting a clinical study in single-case-design to test the effectiveness of an EXP treatment that was specifically designed for the needs and risks of patients with PDN (ActiFeeT, NCT03066570).

There are a few limitations of the current study that should be mentioned. For this systematic review, the search was focused on combined treatments (exercise and psychological). Within the set of articles retrieved, we identified eight articles that discussed exercise or psychological therapies alone. It should be noted that this was not our primary research question and therefore the listing may not be complete. We evaluated the option of performing a new search with the or option, but decided not to do this, as this work has already been done by Davies et al. in 2015 [58]. By performing a thorough hand search through all databases, we identified only one article that was published after the review of Davies et al. [43]. We added this article to our results. Furthermore, we could not retrieve the full text of three remaining articles. Based on the abstracts, we did not expect any added value of these articles (wrong diagnosis and/or design).

In conclusion, PDN is a multifactorial disease in which pain, balance disorders, gait disturbance and fear/avoidance behaviour can significantly limit daily life activities QoL. Current care, mostly based on pharmacotherapy, physical training and/or psychological support, seems insufficient to increase physical activity and regain normal daily functioning. Although studies suggest that a multidisciplinary therapeutic approach could be effective in improving daily life functioning and QoL in patients with PDN, this systematic review of the literature revealed no studies that describe or test treatment modalities that combine exercise therapy with psychological treatment. This empty review highlights the need for studies on the effectiveness of multidisciplinary treatments such as EXP or ACT.

\section{Authors' statements}

Research funding: This work was partially supported by a grant from the Dutch Diabetes Foundation.

Conflict of interest: None of the authors have any financial or other relationship that might lead to a conflict of interest.

Informed consent: Not applicable.

Ethical approval: Not applicable.

\section{References}

[1] Jude EB, Schaper N. Treating painful diabetic polyneuropathy. BMJ 2007;335:57.

[2] Tesfaye S, Vileikyte L, Rayman G, Sindrup SH, Perkins BA, Baconja M, Vinik Al, Boulton AJ. Painful diabetic peripheral neuropathy: consensus recommendations on diagnosis, assessment and management. Diabetes Metab Res Rev 2011;27:629-38.

[3] Boulton AJ, Kirsner RS, Vileikyte L. Neuropathic diabetic foot ulcers. N Engl J Med 2004;351:48-55.

[4] Ziegler D. Treatment of diabetic neuropathy and neuropathic pain: how far have we come? Diabetes Care 2008;31(Suppl. 2):S255-61.

[5] Rosenberg CJ, Watson JC. Treatment of painful diabetic peripheral neuropathy. Prosthet Orthot Int 2015;39:17-28.

[6] Cakici N, Fakkel TM, van Neck JW, Verhagen AP, Coert JH. Systematic review of treatments for diabetic peripheral neuropathy. Diabet Med 2016;33:1466-76.

[7] Schmader KE. Epidemiology and impact on quality of life of postherpetic neuralgia and painful diabetic neuropathy. Clin J Pain 2002;18:350-4.

[8] Peltier A, Goutman SA, Callaghan BC. Painful diabetic neuropathy. BMJ 2014;348:g1799.

[9] Lalli P, Chan A, Garven A, Midha N, Chan C, Brady S, Block E, Hu B, Toth C. Increased gait variability in diabetes mellitus patients with neuropathic pain. J Diabetes Complications 2013;27:248-54.

[10] van Sloten TT, Savelberg HH, Duimel-Peeters IG, Meijer K, Henry RM, Stehouwer CD, Schaper NC. Peripheral neuropathy, decreased muscle strength and obesity are strongly associated with walking in persons with type 2 diabetes without manifest mobility limitations. Diabetes Res Clin Pract 2011;91:32-9.

[11] van Sloten TT, Savelberg HH, Duimel-Peeters IG, Meijer K, Henry RM, Stehouwer CD, Schaper NC. Peripheral neuropathy, decreased muscle strength and obesity are strongly associated with walking in persons with type 2 diabetes without manifest mobility limitations. Diabetes Res Clin Pract 2011;91:32-9.

[12] Geelen CC, Smeets R, Schmitz S, van den Bergh JP, Goossens M, Verbunt JA. Anxiety affects disability and quality of life in patients with painful diabetic neuropathy. Eur J Pain 2017;21:1632-41. 
[13] Kanera IM, van Laake-Geelen CCM, Ruijgrok JM, Goossens MEJB, de Jong JR, Verbunt JA, Geerts M, Smeets RJEM, Kindermans HPJ. Living with painful diabetic neuropathy: insights from focus groups into fears and coping strategies. Psychol Health 2019;34:84-105.

[14] daCosta DiBonaventura M, Cappelleri JC, Joshi AV. A longitudinal assessment of painful diabetic peripheral neuropathy on health status, productivity, and health care utilization and cost. Pain Med 2011;12:118-26.

[15] Davies M, Brophy S, Williams R, Taylor A. The prevalence, severity, and impact of painful diabetic peripheral neuropathy in type 2 diabetes. Diabetes Care 2006;29:1518-22.

[16] Geerts M, Bours G, de Wit R, Landewé S, van Haarlem A, Schaper N. Prevalence and impact of pain in diabetic neuropathy. Eur Diab Nursing 2009;6:58-64.

[17] Vileikyte L, Rubin RR, Leventhal H. Psychological aspects of diabetic neuropathic foot complications: an overview. Diabetes Metab Res Rev 2004;20(S1):S13-8.

[18] Gonzalez JS, Vileikyte L, Ulbrecht JS, Rubin RR, Garrow AP, Delgado C, Cavanagh PR, Boulton AJ, Peyrot M. Depression predicts first but not recurrent diabetic foot ulcers. Diabetologia 2010;53:2241-8

[19] Jain R, Jain S, Raison CL, Maletic V. Painful diabetic neuropathy is more than pain alone: examining the role of anxiety and depression as mediators and complicators. Curr Diab Rep 2011;11:275-84.

[20] Selvarajah D, Cash T, Sankar A, Thomas L, Davies J, Cachia E, Gandhi R, Wilkinson ID, Wilkinson N, Emery CJ, Tesfaye S. The contributors of emotional distress in painful diabetic neuropathy. Diab Vasc Dis Res 2014;11:218-25.

[21] Gore M, Brandenburg NA, Dukes E, Hoffman DL, Tai K-S, Stacey B. Pain severity in diabetic peripheral neuropathy is associated with patient functioning, symptom levels of anxiety and depression, and sleep. J Pain Symptom Manage 2005;30:374-85.

[22] Geelen CC, Kindermans HP, van den Bergh JP, Verbunt JA. Perceived physical activity decline as a mediator in the relationship between pain catastrophizing, disability, and quality of life in patients with painful diabetic neuropathy. Pain Practice 2017;17:320-8.

[23] Colberg SR, Sigal RJ, Fernhall B, Regensteiner JG, Blissmer BJ, Rubin RR, Chasan-Taber L, Albright AL, Braun B. Exercise and type 2 diabetes: the American College of Sports Medicine and the American Diabetes Association: joint position statement executive summary. Diabetes Care 2010;33:2692-6.

[24] Kluding PM, Pasnoor M, Singh R, Jernigan S, Farmer K, Rucker J, Sharma NK, Wright DE. The effect of exercise on neuropathic symptoms, nerve function, and cutaneous innervation in people with diabetic peripheral neuropathy. J Diabetes Complications 2012;26:424-9.

[25] Kluding PM, Pasnoor M, Singh R, Jernigan S, Farmer K, Rucker J, Sharma NK, Wright DE. The effect of exercise on neuropathic symptoms, nerve function, and cutaneous innervation in people with diabetic peripheral neuropathy. J Diabetes Complications 2012;26:424-9.

[26] Thomas DE, Elliott EJ, Naughton GA. Exercise for type 2 diabetes mellitus. Cochrane Database Syst Rev 2006: CD002968.

[27] Dixit S, Maiya A, Shastry B. Effect of aerobic exercise on quality of life in population with diabetic peripheral neuropathy in type 2 diabetes: a single blind, randomized controlled trial. Qual Life Res 2014;23:1629-40.

[28] Praet SF, van Rooij ES, Wijtvliet A, Boonman-de Winter LJ, Enneking T, Kuipers H, Stehouwer CD, van Loon LJ. Brisk walking compared with an individualised medical fitness programme for patients with type 2 diabetes: a randomised controlled trial. Diabetologia 2008;51:736-46.

[29] Melai T, Schaper NC, Ijzerman TH, de Lange TL, Willems PJ, Lima Passos V, Lieverse AG, Meijer K, Savelberg HH. Lower leg muscle strengthening does not redistribute plantar load in diabetic polyneuropathy: a randomised controlled trial. J Foot Ankle Res 2013;6:41.

[30] Geerts M, Landewe-Cleuren SA, Kars M, Vrijhoef HJ, Schaper NC. Effective pharmacological treatment of painful diabetic neuropathy by nurse practitioners: results of an algorithmbased experience. Pain Med 2012;13:1324-33.

[31] Brazeau AS, Rabasa-Lhoret R, Strychar I, Mircescu H. Barriers to physical activity among patients with type 1 diabetes. Diabetes Care 2008;31:2108-9.

[32] Vlaeyen JW, Kole-Snijders AM, Boeren RG, van Eek H. Fear of movement/(re)injury in chronic low back pain and its relation to behavioral performance. Pain 1995;62:363-72.

[33] Leeuw M, Goossens ME, Linton SJ, Crombez G, Boersma K, Vlaeyen JW. The fear-avoidance model of musculoskeletal pain: current state of scientific evidence. J Behav Med 2007;30:77-94.

[34] Verbunt JA, Seelen HA, Vlaeyen JW, van de Heijden GJ, Heuts $\mathrm{PH}$, Pons K, Knottnerus JA. Disuse and deconditioning in chronic low back pain: concepts and hypotheses on contributing mechanisms. Eur J Pain 2003;7:9-21.

[35] Kamper SJ, Apeldoorn AT, Chiarotto A, Smeets RJ, Ostelo RW, Guzman J, van Tulder MW. Multidisciplinary biopsychosocial rehabilitation for chronic low back pain. Cochrane Database Syst Rev 2014:Cd000963. doi: 10.1002/14651858.CD000963. pub3.

[36] Sterne JA, Hernan MA, Reeves BC, Savovic J, Berkman ND, Viswanathan M, Henry D, Altman DG, Ansari MT, Boutron I, Carpenter JR, Chan AW, Churchill R, Deeks JJ, Hrobjartsson A, Kirkham J, Juni P, Loke YK, Pigott TD, Ramsay CR, et al. ROBINSI: a tool for assessing risk of bias in non-randomised studies of interventions. BMJ 2016;355:14919.

[37] Dixit S, Maiya A, Shastry B. Effect of aerobic exercise on quality of life in population with diabetic peripheral neuropathy in type 2 diabetes: a single blind, randomized controlled trial. Qual Life Res 2014;23:1629-40.

[38] Dixit S, Maiya AG, Shastry BA. Effect of aerobic exercise on peripheral nerve functions of population with diabetic peripheral neuropathy in type 2 diabetes: a single blind, parallel group randomized controlled trial. J Diabetes Complications 2014;28:332-9.

[39] Ahn S, Song R. Effects of Tai Chi Exercise on glucose control, neuropathy scores, balance, and quality of life in patients with type 2 diabetes and neuropathy. J Altern Complement Med (New York, NY) 2012;18:1172-8.

[40] Teixeira E. The effect of mindfulness meditation on painful diabetic peripheral neuropathy in adults older than 50 years. Holist Nurs Pract 2010;24:277-83.

[41] Otis JD, Sanderson K, Hardway C, Pincus M, Tun C, Soumekh S. A randomized controlled pilot study of a cognitive-behavioral therapy approach for painful diabetic peripheral neuropathy. J Pain 2013;14:475-82. 
[42] Nathan HJ, Poulin P, Wozny D, Taljaard M, Smyth C, Gilron I, Sorisky A, Lochnan H, Shergill Y. Randomized trial of the effect of mindfulness-based stress reduction on pain-related disability, pain intensity, health-related quality of life, and A1C in patients with painful diabetic peripheral neuropathy. Clin Diabetes 2017;35:294-304.

[43] Davies B, Cramp F, Gauntlett-Gilbert J, Wynick D, McCabe CS. The role of physical activity and psychological coping strategies in the management of painful diabetic neuropathy $-\mathrm{a}$ systematic review of the literature. Physiotherapy (United Kingdom) 2015;101:319-26.

[44] Castelnuovo G, Giusti EM, Manzoni GM, Saviola D, Gatti A, Gabrielli S, Lacerenza M, Pietrabissa G, Cattivelli R, Spatola CA, Corti S, Novelli M, Villa V, Cottini A, Lai C, Pagnini F, Castelli L, Tavola $M$, Torta R, Arreghini M, et al. Psychological considerations in the assessment and treatment of pain in neurorehabilitation and psychological factors predictive of therapeutic response: Evidence and recommendations from the Italian Consensus Conference on Pain in Neurorehabilitation. Front Psychol 2016;7:468.

[45] D’Amato C, Morganti R, Greco C, Di Gennaro F, Cacciotti L, Longo S, Mataluni G, Lauro D, Marfia GA, Spallone V. Diabetic peripheral neuropathic pain is a stronger predictor of depression than other diabetic complications and comorbidities. Diab Vasc Dis Res 2016;13:418-28.

[46] Gore M, Brandenburg NA, Dukes E, Hoffman DL, Tai KS, Stacey B. Pain severity in diabetic peripheral neuropathy is associated with patient functioning, symptom levels of anxiety and depression, and sleep. J Pain Symptom Manage 2005;30:374-85.

[47] Benbow SJ, Wallymahmed ME, Macfarlane IA. Diabetic peripheral neuropathy and quality of life. QJM 1998;91:733-7.

[48] Vlaeyen J, Morley S, Linton SJ, Boersma K, de Jong J. Painrelated fear: exposure based treatment for chronic pain. Seattle, USA: IASP Press, 2012:196

[49] de Jong JR, Vangronsveld K, Peters ML, Goossens ME, Onghena P, Bulte I, Vlaeyen JW. Reduction of pain-related fear and disability in post-traumatic neck pain: a replicated single-case experimental study of exposure in vivo. J Pain 2008;9:1123-34.
[50] den Hollander M, Goossens M, de Jong J, Ruijgrok J, Oosterhof J, Onghena P, Smeets R, Vlaeyen JW. Expose or protect? A randomized controlled trial of exposure in vivo vs pain-contingent treatment as usual in patients with complex regional pain syndrome type 1. Pain 2016;157:2318-29.

[51] Leeuw M, Goossens ME, van Breukelen G), de Jong JR, Heuts PH, Smeets RJ, Koke AJ, Vlaeyen JW. Exposure in vivo versus operant graded activity in chronic low back pain patients: results of a randomized controlled trial. Pain 2008;138:192-207.

[52] Meulders A, Vlaeyen JW. Reduction of fear of movementrelated pain and pain-related anxiety: an associative learning approach using a voluntary movement paradigm. Pain 2012;153:1504-13.

[53] Vlaeyen JW, de Jong J, Leeuw M, Crombez G. Fear reduction in chronic pain: graded exposure in vivo with behavioral experiments. Understanding and treating fear of pain. Oxford, UK: Oxford University Press, 2004:313-43.

[54] de Jong JR, Vlaeyen JW, Onghena P, Cuypers C, den Hollander $M$, Ruijgrok J. Reduction of pain-related fear in complex regional pain syndrome type I: the application of graded exposure in vivo. Pain 2005;116:264-75.

[55] Vlaeyen JW, de Jong J, Geilen M, Heuts PH, van Breukelen G. The treatment of fear of movement/(re) injury in chronic low back pain: further evidence on the effectiveness of exposure in vivo. Clin J Pain 2002;18:251-61.

[56] Hayes SC, Strosahl KD, Wilson KG. Acceptance and commitment therapy: the process and practice of mindful change. New York, USA: Guilford Press, 2011.

[57] McCracken LM, Vowles KE. Acceptance and commitment therapy and mindfulness for chronic pain: model, process, and progress. Am Psychol 2014;69:178-87.

[58] Crombez G, Eccleston C, Van Damme S, Vlaeyen J, Karoly P. Fear-avoidance model of chronic pain: the next generation. Clin J Pain 2012;28:475-83.

Supplementary Material: The online version of this article offers supplementary material (https://doi.org/10.1515/sjpain-2019-0001). 